\title{
PLANEJAMENTO PRÉ-OPERATÓRIO E TÉCNICA CIRÚRGICA DA OSTEOTOMIA SUPRACONDILIANA VARIZANTE DE ADIÇÃO DO FÊMUR PARA CORREÇÃO DO GENO VALGO E FIXAÇÃO COM IMPLANTE DE ÂNGULO FIXO
}

\author{
PRE-OPERATIVE PLANNING AND SURGICAL \\ TECHNIQUE OF THE OPEN WEDGE SUPRACONDYLAR OSTEOTOMY \\ FOR CORRECTION OF VALGUS KNEE AND FIXATION WITH A FIXED-ANGLE IMPLANT
}

Cleber Antonio Jansen Paccola

\section{RESUMO}

É apresentado o planejamento pré-operatório passo a passo da osteotomia de abertura supracondiliana do fêmur para a correção precisa do eixo de carga do membro inferior usando um implante de ângulo fixo (placa lâmina AO 95º). Também é apresentada a técnica cirúrgica e a utilização de enxerto ósseo do próprio local para o preenchimento da falha.

Descritores - Osteotomia; Geno Valgo; Cuidados Pré-Operatórios

\section{ABSTRACT}

The pre-operative planning is presented in a step by step fashion and the surgical technique of the lateral open wedge supracondylar femoral osteotomy for correction of the valgus knee using a fixed angle implant (95 $\mathrm{AO}$ angled blade plate). A surgical method for filling in the defect using an autologous bone graft is also presented.

Keywords - Osteotomy; Genu Valgum; Preoperative Care

\section{INTRODUÇÃO EXPLICATIVA}

A osteotomia femoral distal para correção do geno valgo e artrose predominantemente lateral em paciente abaixo dos 60 anos segue sendo largamente suportada na literatura ${ }^{(1-17)}$.

O procedimento requer planejamento detalhado para se preencher o requisito necessário de uma correção exata e reprodutível. O que se deseja é realinhar o eixo de carga, que une os centros do quadril, joelho e tornozelo, para que passe levemente medial à espinha tibial medial, ou seja, uma leve hipercorreção, conforme mostrado pela literatura para casos de artrose com desvio de eixo mecânico, em que os melhores resultados são aqueles nos quais a deformidade foi levemente hipercorrigida ${ }^{(16)}$.
A técnica mais usada na literatura é a osteotomia de cunha de subtração medial, com fixação com placa lâmina $90^{\circ(5)}$.

A correção através de osteotomia supracondiliana de cunha de abertura e fixação com placa lâmina de $95^{\circ}$ foi primeiro descrita por Postel e Langlais ${ }^{(18)}$. São os únicos autores a descrever um método para se lograr a correção baseado na correta inserção da lâmina no fêmur distal. No procedimento recomendam a inserção de fioguia 20-30mm proximal ao espaço lateral, formando um ângulo com a cortical lateral do fêmur de $95^{\circ}$ menos ao ângulo desejado de correção. Como será demonstrado neste trabalho, esta técnica é inadequada para o realinhamento correto do eixo de carga.

Com o uso do DCS, Andrade et al ${ }^{(11)}$ descrevem técnica colocando o parafuso DCS a $5^{\circ}$ em varo em relação 
à tangente aos côndilos na visão anteroposterior, assumindo que o implante, que tem $5^{\circ}$ entre o parafuso e a placa, irá alinhar o joelho adequadamente, produzindo $5^{0}$ de hipercorreção.

Tanto a osteotomia de cunha de subtração medial quanto a de adição lateral, requerem cuidadoso planejamento para se obter a exata correção pretendida.

O planejamento pré-operatório, parte extremamente importante do procedimento quando se usa um implante de ângulo fixo (placa lâmina 95 , DCS), não foi devidamente explorado na literatura, não havendo trabalho que guie o cirurgião passo a passo no planejamento e que leve à exatidão da correção pretendida.

Da mesma forma, as descrições da técnica cirúrgica não detalham passos importantes. Dentre eles os mais importantes são a colocação do elemento distal de um implante de ângulo fixo de forma correta e como evitar a perda pós-operatória da redução da cortical medial.

Este trabalho tem o objetivo de dissecar passo a passo o planejamento pré-operatório e a técnica empregada para a fixação usando uma placa de ângulo fixo. A placa lâmina $\mathrm{AO} 95^{\circ}$ foi escolhida para ilustrar a técnica neste trabalho, por ser de baixo custo e de maior dificuldade, mas os passos são análogos para outros implantes de ângulo fixo. Além disso, é descrita neste trabalho uma forma de se evitar o retardo de consolidação e o uso de enxertia do ilíaco na grande maioria dos casos.

\section{Descrição do método}

O planejamento pré-operatório é baseado em um AP panorâmico com carga do membro inferior. O paciente de pé apoia-se sobre o lado acometido e o cassete fica posteriormente ao joelho, tomando-se o cuidado para que a patela esteja olhando para frente (o técnico de radiologia tende a posicionar o pé ao invés do joelho!). O cassete deve alcançar desde o quadril até o tornozelo $(1,30 \mathrm{~m})$. É um cassete especial que requer filme também especial, o qual pode ser substituído por vários filmes convencionais em série com as bordas superpostas, colocando-se na superfície externa do cassete alguns clipes de papel nas regiões de superposição das extremidades dos filmes, para facilitar o ajuste de cada filme na devida posição quando da recomposição da vista panorâmica (Figura 1). Muito importante que a ampola seja posicionada a 3m de distância e o raio esteja horizontal, isto é, paralelo ao chão, apontando para o joelho. É imperioso que se obtenha visualização do membro desde o quadril até o tornozelo, para poder-se traçar o eixo de carga do membro (Figura 1).

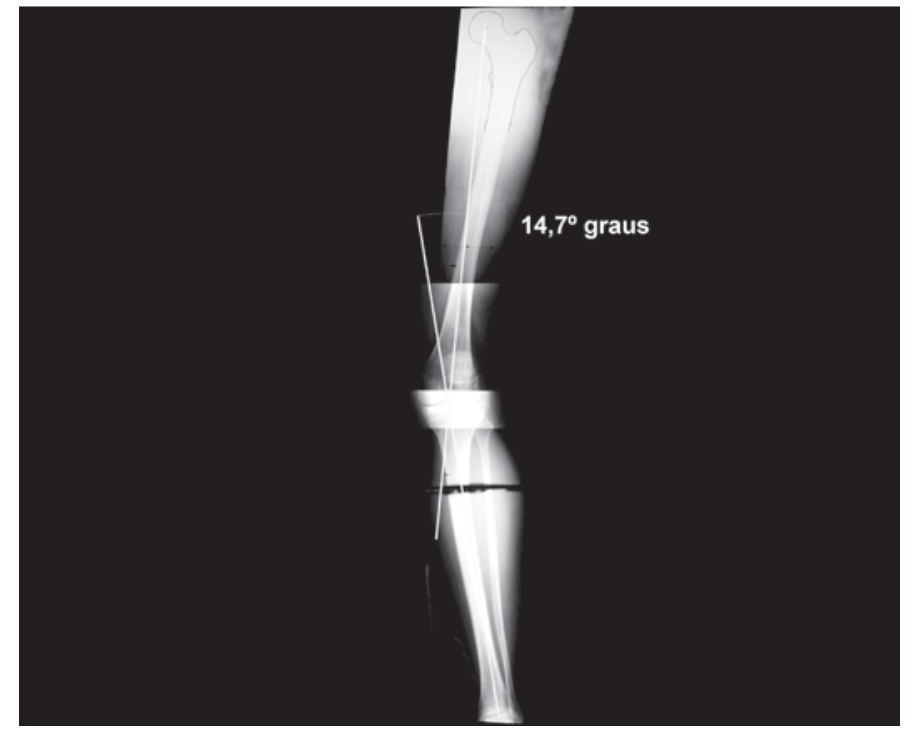

Figura 1 - Radiografia panorâmica em anteroposterior com carga do membro inferior esquerdo, tomando-se o cuidado de manter a patela olhando para frente e o raio incidindo horizontalmente (paralelo ao chão) e mirando no joelho, com a ampola a $3 \mathrm{~m}$ de distância. Nota-se grande desvio do eixo de carga do membro inferior. Entre os eixos de carga femoral e tibial, é possível medir-se um desvio de $14,7^{\circ}$.

O próximo passo é saber se a deformidade é no joelho, usualmente por hipoplasia do côndilo lateral do fêmur, ou por inclinação exagerada dos planaltos, ou ainda por erosão do espaço articular e do próprio planalto lateral, ou mesmo por encurvamento da diáfise do fêmur ou da tíbia.

Para saber-se se a deformidade é ao nível do joelho, ou se ela está mais no fêmur ou na tíbia, traça-se os eixos diafisários, os quais devem se cruzar próximo ao joelho. Quando os eixos diafisários do fêmur e da tíbia não se cruzam no joelho, devem ser pesquisadas outras causas extra-articulares para explicar o geno valgo, por exemplo o encurvamento das diáfises do fêmur ou da tíbia (quando então não é possível traçarse o eixo diafisário mantendo-o sobre o osso). Esta eventualidade pode implicar na existência de um centro extra-articular de deformidade, havendo, portanto, mais de um centro de deformidade, o que pode exigir correção em mais de um sítio, para se evitar, ao final da “correção”, que a interlinha do joelho fique inclinada durante o ortostatismo, mesmo que o eixo mecânico esteja corrigido.

No caso em questão (Figura 1) vê-se que existe leve encurvamento em valgo da tíbia, o que é comum em geno valgo do desenvolvimento. Entretanto, o eixo de carga da tíbia é muito próximo do eixo diafisário, o que indica que a deformidade da diáfise da tíbia é pequena. O desvio do eixo mecânico medido foi de $14,7^{\circ}$. 
O planejamento começa obtendo-se traçado no papel do contorno ósseo da radiografia panorâmica (Figura 2A). No traçado é superposta a transparência da placa lâmina $95^{\circ}$, de forma que a parte reta da placa forme um ângulo com a cortical lateral da diáfise de aproximadamente $15^{\circ}$ (próximo do ângulo medido de desvio do eixo mecânico - Figura 1). Escolhe-se um ponto de entrada para a lâmina, de forma a permitir a inserção de pelo menos um parafuso no fragmento distal, para evitar que a lâmina retroceda ulteriormente. Especialmente no caso de um DCS, este parafuso epifisário proximal ao parafuso DCS é importante para manter o alinhamento no plano sagital (Figura 2B). Deve-se ainda garantir osso distal em espessura suficiente para evitar que a lâmina penetre na articulação. Faz-se então o traçado da osteotomia, iniciando suficientemente proximal para deixar margem suficiente de osso entre a osteotomia e o primeiro parafuso distal. A obliquidade da osteotomia garante maior superfície de corte e menor chance de distúrbios da consolidação (Figura 2C). Para isto, o traçado é inclinado para terminar próximo do epicôndilo medial, em uma região rica em fibras de Sharpey, que ajudam a evitar a perda de contato da cortical medial.

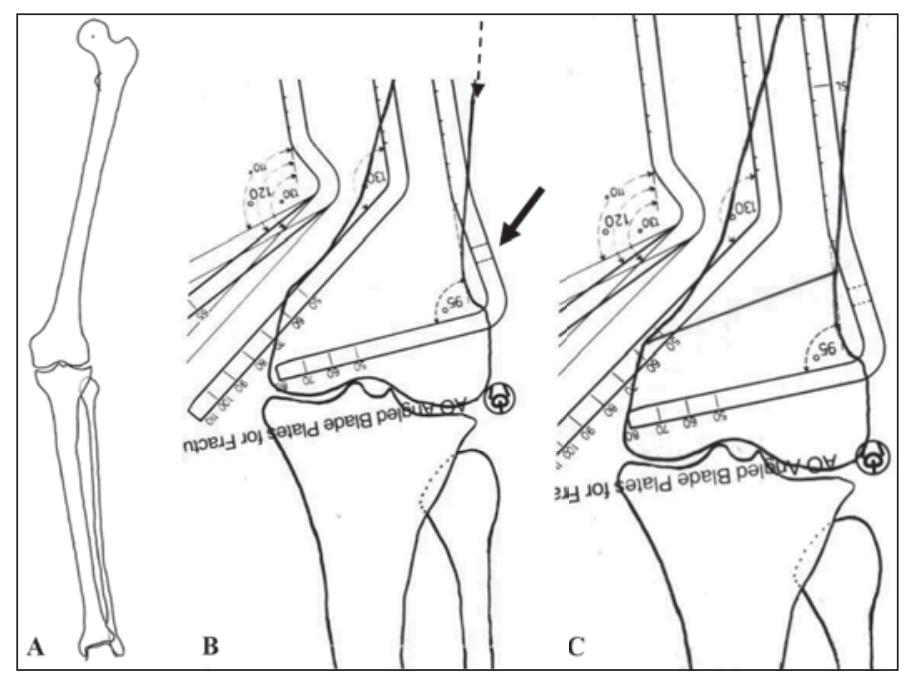

Figura 2 - A) Vê-se o traçado obtido sobre a radiografia panorâmica em AP. B) A superposição da transparência de placas anguladas (no caso $95^{\circ}$ ) para estimar o tamanho da lâmina, garantindo a colocação de um parafuso no segmento distal (seta). Observe que a transparência é colocada formando um ângulo entre a parte reta da placa e a diáfise femoral, aproximadamente igual ao ângulo de desvio medido na radiografia panorâmica (seta pontilhada). C) Vê-se o traçado obliquo da osteotomia, assegurando uma ampla superfície da osteotomia e suficientemente distante do parafuso distal.

Com uma tesoura, corta-se o papel traçado da radiografia panorâmica seguindo o traçado da osteotomia (Figura 2C). Faz-se o alinhamento das três articulações (quadril, joelho e tornozelo), tomando-se o cuidado para provocar leve hipercorreção, fazendo o eixo de carga (barbante tenso) passar levemente medial à espinha medial da tíbia (Figura 3A). O papel é fixado nesta posição com fita adesiva. O ângulo de abertura do papel no local da osteotomia é medido diretamente com um goniômetro (Figura 3C). Este é o ângulo de correção requerido intraoperatoriamente para se obter o resultado desejado $\left(21^{\circ}\right)$. É interessante observar que este ângulo é diferente daquele medido na Figura $1\left(14,7^{\circ}\right)$. Isto se deve à hipercorreção desejada, a qual faz o eixo passar levemente medial à espinha tibial medial.

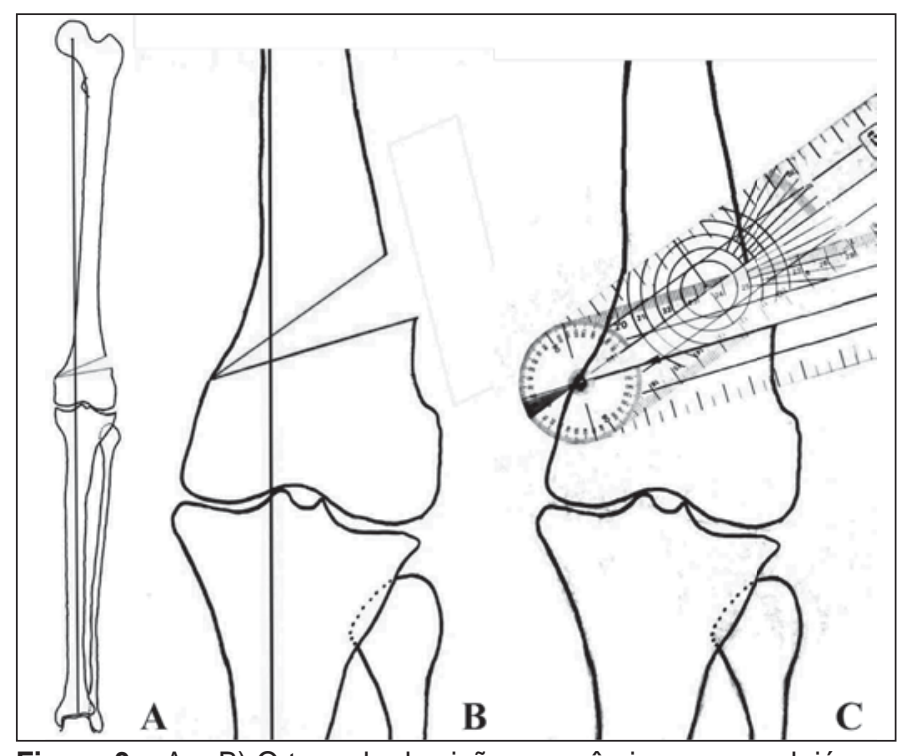

Figura 3 - A e B) O traçado da visão panorâmica em papel, já cortado e alinhado, de forma a obter a correção desejada do eixo de carga, para tê-lo passando levemente medial à espinha medial da tíbia. C) $\mathrm{O}$ ângulo medido com goniômetro fornece a leitura de $21^{\circ}$.

Com o traçado fixado com fita adesiva na posição de correção desejada, faz-se a superposição da transparência da placa lâmina $95^{\circ}$ de forma a garantir a adaptação melhor possível da parte reta da placa na cortical lateral do fêmur e a lâmina na melhor posição, garantindo a inserção de um parafuso epifisário proximal à lâmina (Figura 4A). Isto é necessário para que a correção intraoperatória seja obtida automaticamente quando se adapta a placa à diáfise após a inserção da lâmina da placa $95^{\circ}$. Escolhe-se também o comprimento da placa, de forma a se ter pelo menos quatro parafusos bicorticais proximalmente à osteotomia. Traça-se no papel o contorno da placa na posição escolhida, escolhendo-se a lâmina adequada da lâmina (em geral 60mm).

Em seguida, mede-se o ângulo formado entre a lâmina e a tangente aos côndilos (Figura 4C). Este ângulo tem fundamental importância, pois ele nos indica a 
inclinação da entrada do osteótomo especial (que corta o caminho da lâmina), em relação à tangente aos côndilos femorais distalmente, na vista de frente. Desta forma temos determinados os dois pontos fundamentais no uso de um implante como a placa lâmina $95^{\circ}$ (ou o DCS): o ponto de inserção da lâmina (ou do parafuso DCS) - (Figura 4A), e o ângulo de inserção em relação à tangente distal aos côndilos no AP - (Figura 4C).

O plano pré-operatório pode finalmente ser completado traçando a posição dos parafusos (Figura 4D). Nele estão os parâmetros fundamentais para a execução da osteotomia: ponto de entrada da lâmina, ângulo da lâmina com a tangente distal aos côndilos na vista de frente e o local da osteotomia.

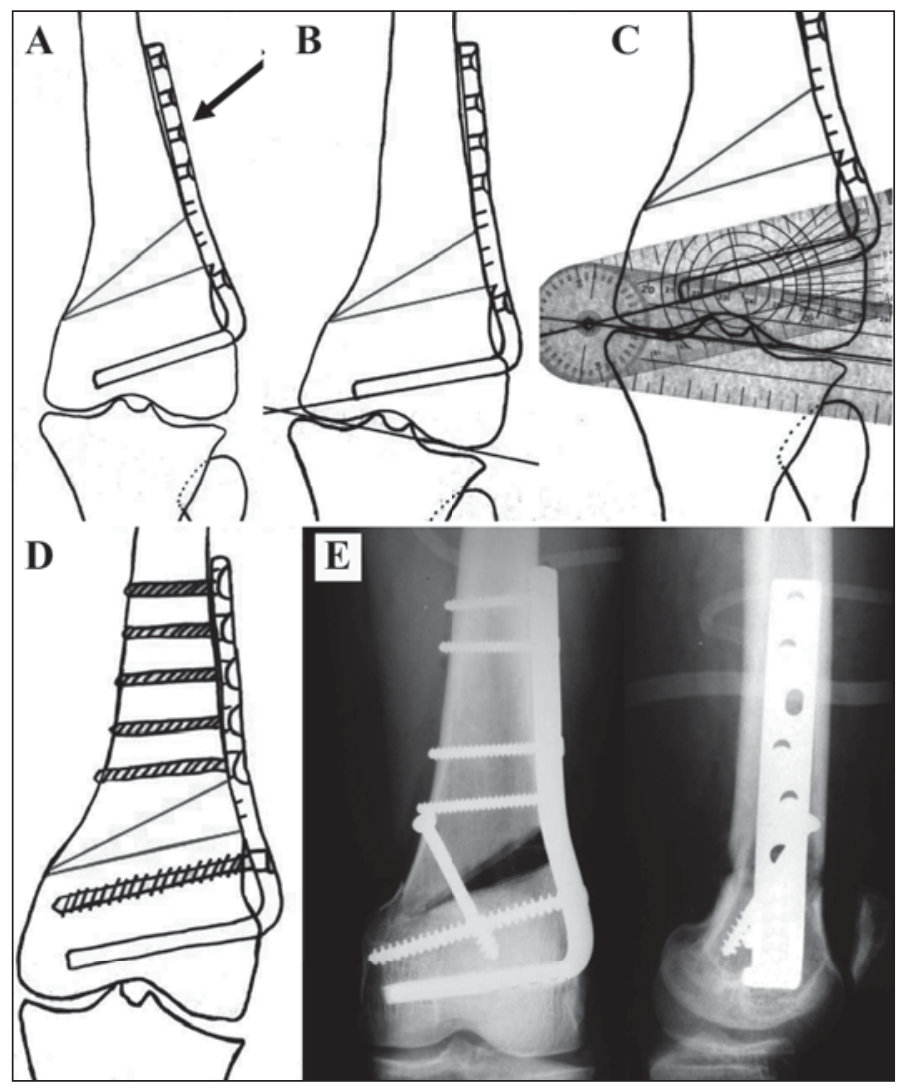

Figura 4 - A) Após a colocação da transparência por debaixo do papel e feito o desenho do contorno da placa escolhida, mantendose o paralelismo da parte reta da placa com a cortical lateral (seta) e assegurando margem necessária de osso para a lâmina não ficar intra-articular e ainda a possibilidade de inserção de um parafuso pela placa no segmento distal. B) São traçadas duas retas: uma tangente distal aos côndilos femorais; e outra, paralela à lâmina da placa. Como se nota na figura, a cortical do fragmento distal próxima à osteotomia e sob a placa usualmente dificulta o assentamento da placa. Esta saliência pode ser judiciosamente removida com serra. C) O ângulo sendo medido com goniômetro, que informa qual é o ângulo de entrada da lâmina em relação à tangente aos côndilos na vista de frente, no caso $21^{\circ}$. D) $O$ traçado final do plano pré-operatório E) $A$ osteotomia executada, notando-se o acréscimo de parafuso medial oblíquo de compressão, para manter a cortical medial (que sempre se fratura) em bom contato, para evitar retardo de consolidação.
Fizemos questão de demonstrar passo a passo a estimativa do ângulo de entrada $\left(21^{\circ}\right)$, que resultaria na correção desejada ao adaptar-se a placa na diáfise, após a introdução da lâmina segundo este ângulo formado entre a lâmina e a tangente aos côndilos distalmente na visão de frente. Coincidentemente, como se vê nas Figuras $3 \mathrm{C}$ e $4 \mathrm{C}$, ele tem o valor de $21^{\circ}$. Em termos práticos, o ângulo de entrada da lâmina deve formar um ângulo com a tangente aos côndilos distalmente, exatamente igual ao medido no papel cortado e corrigido $\left(21^{\circ}\right)$.

Na Figura 5, vê-se o controle pós-operatório de quatro meses do mesmo paciente (Figura 1) usado para exemplificar o planejamento apresentado. Nota-se que, apesar de ter havido fratura da cortical medial na execução da osteotomia (ela sempre ocorre!), isto não representou problema à consolidação, a qual já está bem adiantada e o paciente já estava submetido a carga total.

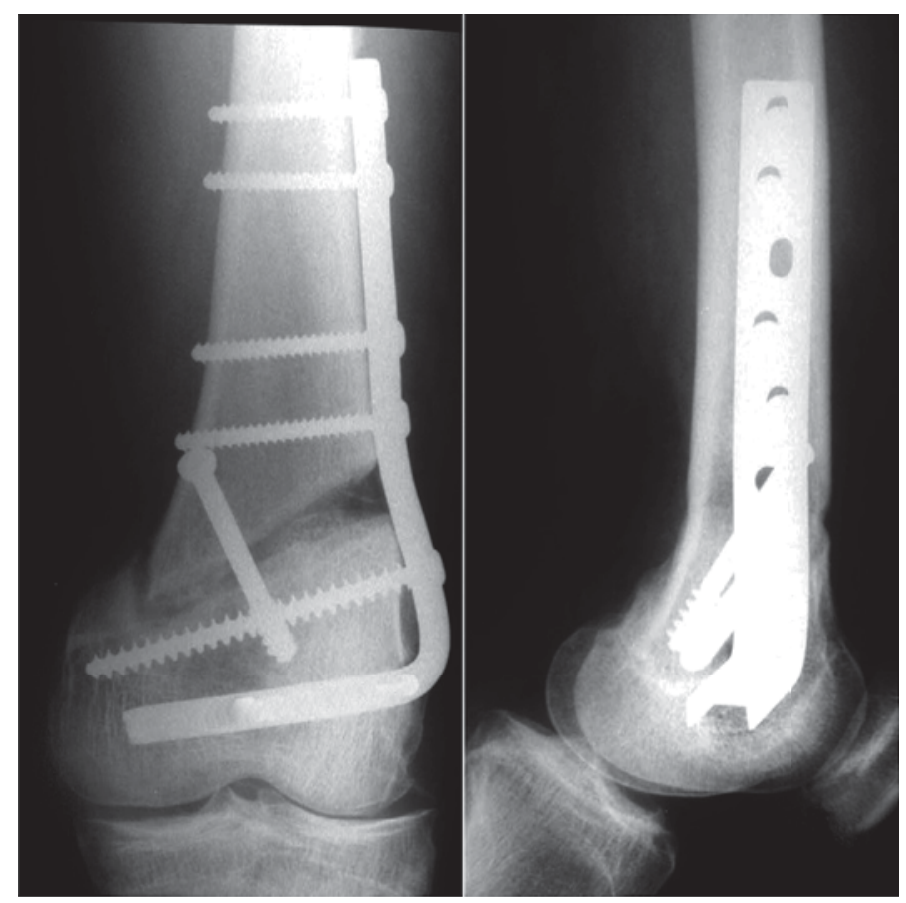

Figura 5 - Controle de quatro meses de pós-operatório, do paciente utilizado no planejamento pré-operatório. A cortical medial, assim como a osteotomia, já se encontra consolidada.

Desta forma o planejamento pré-operatório pode ser assim resumido:

1. Obtenção de radiografia panorâmica com carga em AP do membro inferior;

2. Desenho em papel vegetal longo dos contornos ósseos na radiografia panorâmica;

3. Traçado dos os eixos mecânicos do fêmur e da tíbia e medição do ângulo formado entre eles;

4. Marcação do local da osteotomia sobre o papel tra- 
çado, usando a transparência de placa lâmina $95^{\circ}$, de forma que a parte reta da placa forme um ângulo com a diáfise do fêmur, aproximadamente igual ao medido entre os eixos mecânicos. Desenhar o traçado do corte obliquamente, de forma que seja possível inserir um parafuso no fragmento distal, além da lâmina, e terminando medialmente no epicôndilo medial;

5. Corte do papel no local traçado da osteotomia e alinhamento do traçado, de forma a ter o eixo de carga (barbante tenso) passando levemente medial à espinha medial (leve hipercorreção);

6. Fixação do papel nesta posição com fita adesiva e medição do ângulo de abertura do papel, necessário para obter o alinhamento desejado. Este deve ser o ângulo de entrada da lâmina em relação à tangente aos côndilos distalmente, na visão de frente;

7. Colocação da transparência de placa lâmina $95^{\circ}$ por baixo do papel, de forma que a parte diafisária da placa se adapte bem à cortical lateral do fêmur e seja possível colocar um parafuso na parte distal, além da lâmina, e que haja margem de osso distal para evitar a penetração da lâmina no joelho;

8. Desenho do contorno da placa e dos parafusos. Em geral, uma placa de sete orifícios é a escolhida (Figura 5D).

Assim, os pontos importantes do planejamento estão determinados:

- Ponto de entrada da lâmina;

- Ângulo da lâmina com a tangente distal aos côndilos;

- Local da osteotomia.

\section{Procedimento cirúrgico}

O paciente é colocado em mesa radiotransparente, que permita a visualização radioscópica desde o quadril até o tornozelo.

O uso de torniquete é bastante recomendável para boa visualização e para evitar perda importante de sangue, que é usual neste tipo de cirurgia, quando realizada sem torniquete.

A viabilidade do uso de torniquete pneumático deve ser analisada, o que requer uma coxa suficientemente longa e a ausência de obesidade excessiva.

Em pacientes com coxa curta ou obesos, ainda assim é possível o uso de torniquete. Para isto, o paciente deve ser preparado como para cirurgia no quadril. Um pino de Schanz é inserido na cortical lateral da região subtrocantérica, de forma a permitir a ancoragem proximal de passadas oblíquas sucessivas de faixa de Esmarch de $10 \mathrm{~cm}$ de largura. Com isto se obtém comprimento sufi- ciente de coxa distalmente ao torniquete, para permitir o acesso adequado.

O pé e a metade distal da perna são isolados com campos estéreis, ficando o joelho livre.

A pela é aberta desde o tubérculo de Gerdy em linha com a banda iliotibial na projeção do septo posterolateral, até $15 \mathrm{~cm}$ proximalmente.

A fáscia lata é aberta longitudinalmente, imediatamente anterior ao septo posterolateral e à banda iliotibial.

O músculo vasto lateral é afastado para frente, de forma a preservar o periósteo inserido no osso e evitando agredir a gordura existente anteriormente sob o quadríceps. Logo na região supracondiliana a artéria e veia genicular superior devem ser identificadas e seccionadas após cauterização. O músculo vasto lateral vai sendo desinserido progressivamente das suas inserções no septo e no osso em direção proximal, tomando-se o cuidado de identificar e cauterizar os vasos perfurantes antes de seccioná-los.

A cápsula articular do joelho é aberta em linha com a incisão, tomando-se o cuidado com a inserção dos ligamentos no epicôndilo e com o tendão do poplíteo. A abertura capsular é útil para se inspecionar o menisco lateral e o compartimento lateral do joelho e ainda para se inspecionar e palpar a facies patellaris e prevenir eventual penetração da lâmina na articulação.

O ponto de inserção da lâmina é determinado, segundo o plano pré-operatório e com o auxílio do intensificador de imagem. Neste local abre-se uma janela retangular para a entrada da lâmina de $1,5 \mathrm{~cm}$ de altura por $5 \mathrm{~mm}$ de largura.

Os fios de referência usuais para a inserção da placa lâmina $95^{\circ}$ são posicionados com o joelho flexionado de 45 a $60^{\circ}$. O primeiro, tangenciando os côndilos femorais distalmente na vista de frente (checada sua posição com o intensificador de imagem) e outro, tangenciando a facies patellaris anteriormente. As partes moles mantêm estes fios no lugar, desde que sejam colocados transfixando-as.

Um terceiro fio de referência é passado a meia distância entre a janela feita para a lâmina e a margem articular. Ele deve ser paralelo no plano sagital ao fio tangente à facies patellaris anteriormente. No plano coronal ele deve ser inserido inclinado em direção distal em relação ao fio tangente aos côndilos, segundo o ângulo medido na Figura 5C. Este é o principal fio de referência para a introdução da lâmina e só é removido após a introdução definitiva da placa. Para a sua correta inserção deve-se dispor de cunhas metálicas para medir-se o ângulo for- 
mado com o fio tangente aos côndilos distalmente. Os demais fios podem então ser removidos.

A inserção da lâmina é então feita usando as ferramentas apropriadas, observando-se o paralelismo com o fio de referência e a posição do guia em relação à diáfise para evitar a divergência da placa no plano lateral em relação à diáfise.

Como muitas vezes trata-se de osso de jovem, é prudente inserir-se o formão da lâmina alguns milímetros e proceder-se à remoção parcial, para então inserir-se um pouco mais, novamente removendo, dividindo-se o processo em duas ou três etapas. Isto evita o encarceramento do formão no osso de boa qualidade destes pacientes, o que pode acarretar grande dificuldade para removê-lo. Ao final da confecção do caminho da lâmina, o formão é removido.

O desenho da osteotomia é então feito na cortical anterior com a ajuda do intensificador e do plano préoperatório (Figura 4B), usando o eletrocautério, evitando seccionar a gordura subquadricipital, que é parcimoniosamente elevada com o periósteo e protegida com Hohmann apropriado. O periósteo posterior na linha da osteotomia é elevado, colocando-se um Hohman protegendo as estruturas posteriores na linha da osteotomia.

Três fios de Kirschner paralelos, de 1,5mm de calibre, são introduzidos pela cortical lateral, seguindo o traçado da osteotomia, chegando até a cortical medial, sob controle radioscópico. Eles servirão de apoio à lâmina da serra. A lâmina da serra entra cranialmente tangenciando estes fios, os quais evitam que a lâmina se desvie inadvertidamente do traçado e possa se dirigir para a articulação.

A osteotomia é feita no traçado tomando-se o cuidado de irrigar continuamente com salina, para evitar aquecimento excessivo e morte óssea térmica. O avanço da lâmina da serra é controlado por radioscopia. A lâmina da serra deve chegar até cerca de $1 \mathrm{~cm}$ do limite medial. Durante a osteotomia, um auxiliar exerce leve tensão em varo no joelho para evitar o aprisionamento da lâmina na osteotomia e para sentir quando esta se completa, fraturando a cortical medial. Para a secção da cortical posterior, o joelho deve estar fletido a cerca de $45^{\circ}$ para relaxar as estruturas posteriores. Neste passo nada deve estar pressionando as partes moles posteriores para frente no nível da osteotomia.

A placa escolhida é então inserida no caminho da lâmina previamente confeccionado a golpes leves de martelo, observando atentamente o fio de Kirschner guia, introduzindo assim a lâmina no caminho previa- mente confeccionado. É muito importante que, durante as marteladas para inserção da lâmina, um auxiliar exerça apoio medial vigoroso, para evitar a perda de redução da cortical medial.

Pouco antes da inserção final da lâmina, pode ser necessário remover a saliência da cortical lateral do segmento distal que impede o bom assentamento final da placa (Figura 4B), o que pode ser feito facilmente com serra.

O primeiro parafuso a ser inserido é o epifisário, seguindo o paralelismo à lâmina, sendo recomendado utilizar um parafuso 6,5mm de esponjosa de rosca total. Este parafuso irá evitar o retrocesso da lâmina e dar maior controle do segmento epifisário no plano sagital.

O alinhamento final do membro é feito em extensão do joelho, esticando o fio do eletrocautério, colocando o joelho alinhado com o centro da cabeça femoral e com o centro do tornozelo, checando com radioscopia. O fio deve então passar levemente medial à espinha tibial medial (leve hipercorreção). Ajuste fino do alinhamento desejado é conseguido por manobras feitas por um auxiliar forçando levemente o joelho em varo. É importante garantir que a correção do valgo ocorra só na osteotomia e não (em parte) às custas de uma abertura ligamentar lateral. Para isto, ao mesmo tempo que um auxiliar exerce um leve esforço em varo, a osteotomia é forçada em abertura com dois osteótomos largos, o que garante o fechamento do espaço articular lateral, garantindo que a correção ocorre apenas na osteotomia.

Por vezes se percebe que a banda iliotibial e o septo intermuscular posterolateral resistem e impedem as manobras corretivas. Nestes casos, o alongamento da banda e do septo pode ser feito por múltiplos pequenos piques transversais com bisturi lâmina 15 em níveis diferentes, fazendo os diferentes feixes de fibras deslizarem entre si, de forma a não se perder a continuidade.

Com este alinhamento conseguido, é inserido o primeiro parafuso cortical proximal, adjacente à osteotomia. Usa-se o guia de compressão DCP amarelo na posição invertida (posição de neutralização), para impedir o fechamento da abertura da osteotomia com consequente perda de correção.

Novamente se checa o alinhamento das três articulações. Se tudo bem, os demais parafusos são introduzidos, a partir do mais cranial, de forma bicortical. Todos devem ser inseridos na posição de neutralização (guia amarelo excêntrico invertido na perfuração).

Como medida preventiva para evitar a perda da redução da cortical medial, o que pode resultar em retardo 
de consolidação, a inserção de parafuso de compressão pressionando a cortical medial é eficaz ${ }^{(19)}$. O uso de parafuso canulado facilita em muito este passo. O fio-guia é inserido na cortical medial do fêmur percutaneamente, dirigindo-se o fio para lateral e levemente para trás, para não colidir com a lâmina e atingir a parte posterior do côndilo lateral (Figura 5).

Terminada a fixação, atenção é dada ao espaço criado com a falha óssea na osteotomia. Como regra, a menos que este espaço seja exageradamente grande (maior que 20mm), o que é exceção, o espaço pode ser preenchido com espuma de gelatina (Gelfoam) e, na superfície do Gelfoam, no nível da cortical, coloca-se enxerto autólogo de esponjosa removido da duas superfícies de corte da osteotomia (Figura 6), para haver rápida reconstituição da cortical. Este enxerto é removido cuidadosamente das superfícies esponjosas das superfícies de corte osteotomia, usando osteótomo afiado e removendo pequenas lâminas de 2-3mm de espessura. A espuma de gelatina, além de ajudar na hemostasia, mantém os enxertos no nível da cortical.
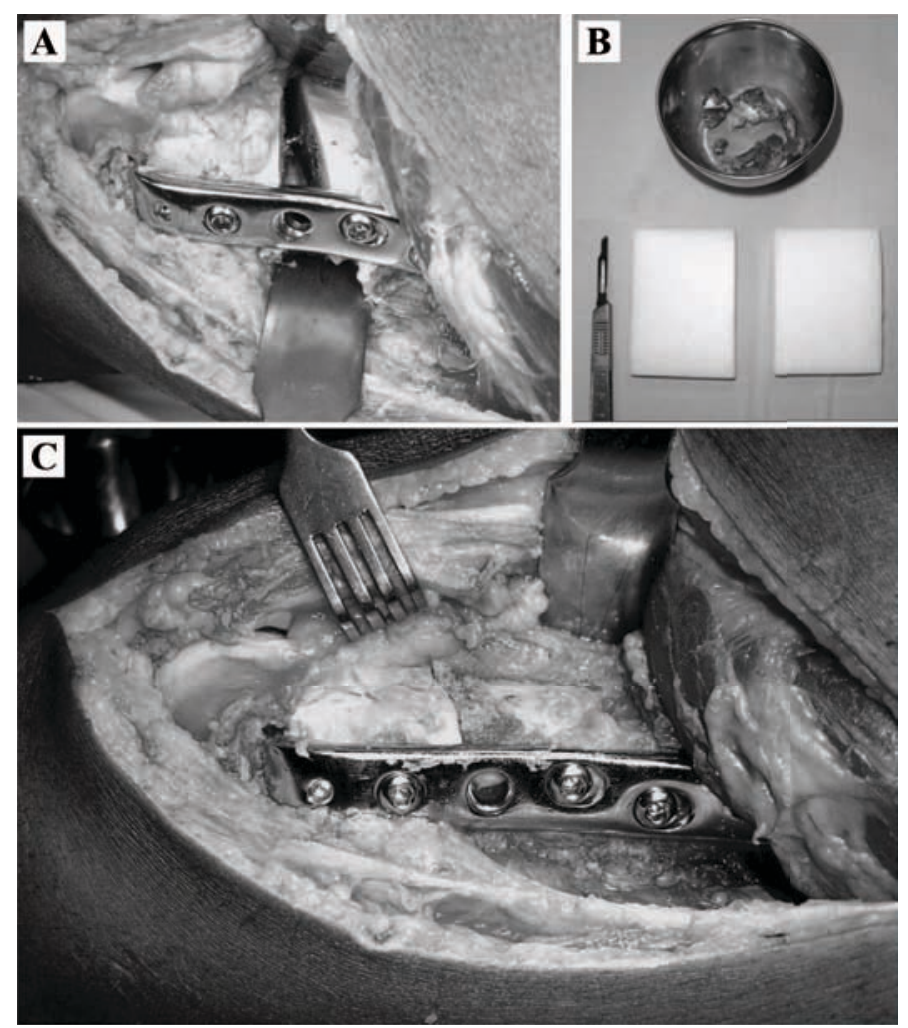

Figura 6 - A) A osteotomia fixada, podendo-se ver as superfícies de corte da osteotomia, de onde serão retiradas lâminas de $2-3 \mathrm{~mm}$ de espessura de osso esponjoso de cada lado, com o auxílio de um osteótomo afiado. B) O osso que foi removido e o Gelfoam que será inserido no espaço após umedecimento. (C) o Gelfoam já inserido e o osso esponjoso colocado no nível das corticais.
Agordura subquadricipital é suturada de forma a conter os fragmentos de osso esponjoso. O torniquete é removido.

Após meticulosa hemostasia a ferida é fechada por planos deixando drenos de aspiração no espaço submuscular, que são removidos em 24 horas. O joelho é posicionado fletido a $90^{\circ}$.

\section{Cuidados pós-operatórios}

O paciente é colocado com o membro operado na posição mantendo o joelho e o quadril flexionados a $90^{\circ}$, a qual deve ser a posição preferencial de repouso nas duas primeiras semanas, para evitar-se a aderência do quadríceps na posição estendida, com resultante dificuldade da recuperação da flexão.

Após a remoção dos drenos o paciente pode receber alta, usando andador, com a autorização de carga até $20 \mathrm{~kg}$, aprendida usando uma balança. Exercícios duas vezes ao dia para aumentar o arco de movimento são ensinados ao paciente. Orienta-se ao paciente manter o joelho fletido além de $60^{\circ}$ a maior parte do dia, para evitar a aderência do quadríceps na posição de extensão, com grande dificuldade de se conseguir a extensão ulteriormente.

A falha óssea deixada pela osteotomia é fechada lentamente, de medial para lateral, ao cabo de muitos meses ou anos.

Alongamentos cuidadosos em extensão e em flexão, feitos duas vezes ao dia, pelo próprio paciente, são suficientes para aumentar o arco de movimentos na grande maioria dos pacientes. Eventualmente, é necessário o auxílio de um fisioterapeuta.

Se tudo está prosseguindo bem, a primeira radiografia de seguimento é feita com oito semanas, quando a cortical medial deve estar consolidada, podendo então a carga ser aumentada progressivamente e os suportes externos removidos na medida da tolerância.

Algumas vezes a placa pode ficar saliente em seu cotovelo, especialmente em pacientes magros. Remoção da placa só pode ser considerada segura quando pelo menos 50\% da largura da osteotomia no AP estiver preenchida por osso, o que leva cerca de dois anos.

Como a placa fica saliente sob o trato iliotibial, ela pode excepcionalmente originar desconforto para alguns pacientes. No entanto, a placa não deve ser removida antes de dois anos, sob risco de fratura no local da falha óssea. Neste meio tempo, medidas de alívio, como antiinflamatórios locais ou sistêmicos e, a cada três meses, uma infiltração com corticoide, podem ajudar a aliviar este período até a remoção da placa. 


\section{COMENTÁRIOS FINAIS}

A osteotomia lateral de adição para correção do geno valgo tem a vantagem de permitir pequenos ajustes, apenas pela maior ou menor abertura da cunha no intraoperatório. Já a cunha de subtração medial torna-se muito problemática para remediar, quando a remoção da cunha não foi perfeita. Outra vantagem da osteotomia de abertura lateral é a facilidade do acesso, o mesmo comumente usado para as fixações das fraturas supracondilianas.

A osteotomia distal do fêmur com implantes de ângulo fixo requer planejamento pré-operatório rigoroso e sistemático, quando se deseja obter correções precisas, em que o mau alinhamento deve ser levemente hipercorrigido, como é o desejável ${ }^{(5-7,17)}$.

A placa lâmina $\mathrm{AO}$ de $95^{\circ}$ tem a vantagem, se colocada corretamente, de garantir a precisa correção pretendida. Não encontramos na literatura o necessário detalhamento deste difícil planejamento. Por esta razão, julgamos adequado e oportuno divulgar este método que, em nossas mãos, tem sido de grande precisão e reprodutibilidade.

O método descrito por Postel e Langlais ${ }^{(18)}$ de preconizar simplesmente adicionar $95^{\circ}$ ao ângulo de correção pretendido, como referência da entrada da lâmina em relação ao eixo diafisário, pressupõe que a inclinação da interlinha do fêmur é o único causador do valgo. No exemplo da Figura 1 vê-se o usual encurvamento da tíbia e o estreitamento do espaço lateral, que não são levados em conta no método dos AA mencionados.

Andrade et $a^{(11)}$ se preocuparam em provocar cerca de $5^{\circ}$ de hipercorreção, quando preconizam entrar com o parafuso DCS a $5^{\circ}$ em varo em relação à tangente distal aos côndilos femorais. No entanto, eles não levaram em conta a possibilidade de haver componente da deformidade além do fêmur distal, o que levaria certamente a um realinhamento inadequado do eixo.

A única forma de corretamente estimar o ângulo de desvio é na radiografia em AP panorâmico com carga. Como demonstrado no nosso planejamento, o ângulo de correção deve ser aquele medido na radiografia panorâmica, acrescido de $3-7^{\circ}$ para causar uma leve hipercorreção. O ângulo de entrada da lâmina deve ser tal que permita a perfeita adaptação da parte reta da placa na diáfise, quando o eixo estiver no alinhamento pretendido. Para se conseguir isto, nada melhor que, no desenho no papel, fazer-se a correção desejada e então superpor-se a transparência do implante desejado com adaptação perfeita com a diáfise lateral.
O princípio da fixação se baseia na adaptação adequada da placa na diáfise, que deve ocorrer apenas na posição corrigida, caso contrário, a correção é imprevisível. Por isto é tão crítico o ângulo de entrada da lâmina da placa $95^{\circ}$ ou do parafuso do DCS, em relação à tangente aos côndilos femorais distalmente.

A correção de mau alinhamento e da necessária correção não deve se basear apenas na medida do ângulo formado entre os eixos de carga do fêmur e da tíbia (Figura 1). A medida correta só é obtida após cortar o papel na provável linha da osteotomia e corrigindo o eixo de carga no desenho em papel obtido da visão panorâmica, fazendo-se então a correção do eixo, de forma a obter-se um eixo passante levemente medial à espinha tibial medial (leve hipercorreção). No nosso exemplo escolhido para ilustração, a diferença foi de $14,7^{\circ}$ para $21^{\circ}$, o que provocaria um erro importante, caso seguíssemos apenas o desvio do eixo de carga do membro inferior medido a partir dos eixos de carga do fêmur e da tíbia.

Outro aspecto que contribui para erro é que, na radiografia com carga, o espaço medial pode estar alargado por frouxidão ligamentar medial eventualmente existente. Daí a necessidade de se provocar leve hipercorreção, o que favorece o fechamento medial durante o suporte de carga, além da efetiva transferência de carga para o compartimento medial, mais preservado. Porém, o ângulo da fenda articular, que normalmente é de $0-2^{\circ}$, quando aumentado medialmente, deve ser subtraído da correção calculada, uma vez que a linha medial irá se fechar devido à hipercorreção. Se este aspecto não for levado em consideração, isto pode implicar em falsa estimativa da correção, com consequente hipercorreção nos casos de frouxidão ligamentar medial. A menos que o ângulo da fenda articular esteja muito aumentado medialmente, pequenos ajustes podem ser conseguidos intraoperatoriamente apenas abrindo ou fechando um pouco a fenda da osteotomia.

A escolha do implante depende da preferência do cirurgião e da disponibilidade. Independente de qualquer implante, o planejamento com a transparência correspondente é essencial, quando se emprega um implante de ângulo fixo (placa lâmina 95 , DCS), em que o elemento de fixação mais importante da parte distal tem que ser inserido com alta precisão. Outros implantes como o Tomofix ou a placa de Puddu, são mais liberais no planejamento, uma vez que irão se adaptar à correção conseguida com manobras intraoperatórias. Infelizmente esta vantagem pode ser pouca, quando se considera 
a menor pega no fragmento distal e menor controle da posição, tanto no plano sagital, quanto no plano frontal, com a fixação com estes implantes.

Mesmo com o uso de implantes de ângulo fixo robustos como o DCS ou a placa lâmina $95^{\circ}$, a manutenção da redução da cortical medial não pode ser assegurada. Por este motivo o acréscimo de parafuso de compressão mantendo a cortical oposta fechada é muito importante ${ }^{(19)}$.

Também a necessidade de inserção de um parafuso no segmento distal pela placa, além da lâmina, principalmente no caso do parafuso DCS, é vital para o controle do segmento distal no plano sagital.

O uso de enxerto esponjoso removido da própria osteotomia vem sendo usado em nossa clínica há muito tempo, com excelentes resultados. Quando a falha não é maior que $15 \mathrm{~mm}$ na cortical lateral, esta técnica é plenamente satisfatória. Questionamento poderia surgir sobre o prejuízo do preenchimento ulterior da falha pela remoção de osso. Isto pode ocorrer, porém não é relevante, desde que a parte medial da osteotomia se consolide. Se isto não ocorrer, mesmo preenchendo completamente a

\section{REFERÊNCIAS}

1. Aglietti P, Menchetti PP. Distal femoral varus osteotomy in the valgus osteoarthritic knee. Am J Knee Surg. 2000;13(2):89-95.

2. Aglietti P, Stringa G, Buzzi R, Pisaneschi A, Windsor RE. Correction of valgus knee deformity with a supracondylar V osteotomy. Clin Orthop Relat Res. 1987;(217):214-20.

3. Amendola A, Bonasia DE. Results of high tibial osteotomy: review of the literature. Int Orthop. 2010;34(2):155-60.

4. Franco V, Cipolla M, Gerullo G, Gianni E, Puddu G. Open wedge osteotomy of the distal femur in the valgus knee. Orthopade. 2004;33(2):185-92.

5. Hofmann S, Lobenhoffer P, Staubli A, Van Heerwaarden R. Osteotomies of the knee joint in patients with monocompartmental arthritis. Orthopäde. 2009;38(8):755-69.

6. Kosashvili Y, Safir O, Gross A, Morag G, Lakstein D, Backstein D. Distal femoral varus osteotomy for lateral osteoarthritis of the knee: a minimum ten-year follow-up. Int Orthop. 2010;34(2):249-54.

7. Koshino T. Osteotomy around young deformed knees: 38-year super-long-term follow-up to detect osteoarthritis. Int Orthop. 2010;34(2):263-9.

8. Learmonth ID. A simple technique for varus supracondylar osteotomy in genu valgum. J Bone Joint Surg Br. 1990;72(2):235-7.

9. Marin Morales LA, Gomez Navalon LA, Zorrilla Ribot P, Salido Valle JA. Treatment of osteoarthritis of the knee with valgus deformity by means of varus osteotomy. Acta Orthop Belg. 2000;66(3):272-8.

10. Omidi-Kashani F, Hasankhani IG, Mazlumi M, Ebrahimzadeh MH. Varus distal femo- falha com enxerto ou outro substituto ósseo, não será suficiente para evitar a pseudartrose ${ }^{(19)}$. Por esta razão, a técnica mencionada de uso de parafuso canulado medial, fazendo compressão e mantendo a cortical medial bem aposta é essencial para evitar a complicação. Temos adotado este princípio para todas as osteotomias ao redor do joelho, especialmente nas cunhas de abertura, como forma de evitar a pseudartrose e o retarde.

A impacção da cortical medial para dentro do fragmento distal, como forma de diminuir a falha e o risco de pseudartrose, como preconizado por Postel e Langlais ${ }^{(18)}$ tem o inconveniente de gerar degrau logo acima da facies patellaris, criando dificuldade no deslizamento da patela, além de encurtamento do membro.

Como conclusão final, diríamos que a osteotomia do fêmur distal para tratamento do geno valgo e da artrose predominantemente lateral do joelho, deve ser meticulosamente planejada, não apenas para a correta estimativa da necessidade de correção, como a adequada execução do procedimento, especialmente quando se emprega um dispositivo de fixação de ângulo fixo. ral osteotomy in young adults with valgus knee. J Orthop Surg Res. 2009;4:15.

11. Andrade MAP, Gomes DC, Portugal AL, Silva GM. Osteotomia femoral distal de varização para osteoartrose no joelho valgo: seguimento em longo prazo. Rev Bras Ortop. 2009;44(4):346-50.

12. Terry GC, Cimino PM. Distal femoral osteotomy for valgus deformity of the knee. Orthopedics. 1992;15(11):1283-9.

13. Wang JW, Hsu CC. Distal femoral varus osteotomy for osteoarthritis of the knee. J Bone Joint Surg Am. 2005;87(1):127-33.

14. Wang JW, Hsu CC. Distal femoral varus osteotomy for osteoarthritis of the knee. Surgical technique. J Bone Joint Surg Am. 2006;88(Suppl 1 Pt 1):100-8.

15. Wang JW, Hsu CC. Distal femoral varus osteotomy for osteoarthritis of the knee. J Bone Joint Surg Am. 2005 Jan; 87(1):127-33.

16. Waugh W. Tibial osteotomy in the management of osteoarthritis of the knee. Clin Orthop Relat Res. 1986;(210):55-61.

17. Zilber S, Larrouy M, Sedel L, Nizard R. Distal femoral varus osteotomy for symptomatic genu valgum: long-term results and review of the literature. Rev Chir Orthop Reparatrice Appar Mot. 2004;90(7):659-65.

18. Postel M, Langlais F. Osteotomies du genou pour gonarthrose. In: Encyclopédie Médico-Chirurgicale: Techniques Chirurgicales, Orthopédie. Paris: Editions Techniques; 1977.p.1-17.

19. Paccola CAJ, Fogagnolo F. Open-wedge high tibial osteotomy- A technical trick to avoid loss of reduction of the opposite cortex. Knee Surg Sports Traumatol Arthrosc. 2005;13:19-22. 